Review Article

\title{
Exploitation of Ultrahigh-Performance Fibre-Reinforced Concrete for the Strengthening of Concrete Structural Members
}

\author{
Mohammed A. Al-Osta \\ King Fahd University of Petroleum and Minerals, Department of Civil and Environmental Engineering, P.O. Box 1498, \\ Dhahran 3126, Saudi Arabia \\ Correspondence should be addressed to Mohammed A. Al-Osta; malosta@kfupm.edu.sa
}

Received 10 August 2017; Accepted 7 November 2017; Published 28 January 2018

Academic Editor: Peng Zhang

Copyright (c) 2018 Mohammed A. Al-Osta. This is an open access article distributed under the Creative Commons Attribution License, which permits unrestricted use, distribution, and reproduction in any medium, provided the original work is properly cited.

\begin{abstract}
The repair and strengthening of reinforced concrete members are very important due to several factors, including unexpected increases in load levels and/or the damaging impact of aggressive environmental conditions on structural concrete members. Many researchers have turned to using materials for the repair and strengthening of damaged structures or the construction of new concrete structural members. Ultrahigh-performance fibre-reinforced concrete (UHPFRC), characterized by superior structural and durability performance in aggressive environmental conditions, is one of the materials that have been considered for the repair and strengthening of concrete structural members. The repair or strengthening of concrete structures using UHPFRC needs a thorough knowledge of the behaviour of both the strengthening material and the strengthened concrete structure at service load conditions, in addition to an understanding of the design guidelines governing the use of such materials for effective repair and strengthening. In this study, the recent issues and findings regarding the use of UHPFRC as a repair or strengthening material for concrete structural members are reviewed, analysed, and discussed. In addition, recommendations were made concerning areas where future attention and research on the use of UHPFRC as a strengthening material needs to be focused if the material is to be applied in practice.
\end{abstract}

\section{Introduction}

Reinforced concrete (RC) structural members are made to efficiently support loads over the expected service life of the structural members. Nevertheless, due to many faults in design, change of usage, poor quality of the materials used, or change in the natural conditions, some of these structural members should be repaired or strengthened. Repair of RC elements is imperative, not only for weakened elements but also for strengthening new structural concrete elements; thereby, strengthened structural elements could safely support the design load under different aggressive environmental conditions without excessive damage.

Over the last two decades, researchers have created different materials and methods for the repair of deteriorated RC members besides strengthening new concrete structural members. Among the most common of the utilized materials is carbon fibre-reinforced polymer (CFRP).
Investigations were directed into strengthening structural members with CFRP and came up with many helpful outcomes. El-Enein et al. [1] investigated the flexural behaviour of an RC slab column joint strengthened with CFRP at the tension side. The results indicated that there is an increment in the flexural capacity and stiffness of the RC slab column joint. Monti and Liotta [2] conducted experimental and analytical works on the shear behaviour of strengthened RC beams with CFRP. The results demonstrated the promising shear enhancement of strengthened RC beams as compared to the control beam. Moreover, design equations have been developed for repairing beams with CFRP. Many research works have been, and are also currently being, directed at the viability of utilizing CFRP as a repair material. In any case, making repairs with CFRP involves deficiencies, which prevent the implementation of CFRP in compression under cyclic loading. This behaviour relies upon the strength of the parent concrete, the CFRP concrete bonds, and their 
TABLE 1: UHPFRC mix design used to strengthen RC beams in torsion [13].

\begin{tabular}{lc}
\hline Material & Mix proportion $\left(\mathrm{kg} / \mathrm{m}^{3}\right)$ \\
\hline Cement & 657 \\
Silica fume & 119 \\
Silica sand & 1051 \\
Superplasticizer (S.P.) & 59 \\
Water & 185 \\
$3 \%$ steel fibres & 236 \\
\hline
\end{tabular}

TABle 2: Mix design of reactive powder concrete (RPC) or the patented name Ductal (RPC) [14].

\begin{tabular}{lc}
\hline Material & Mix proportion $\left(\mathrm{kg} / \mathrm{m}^{3}\right)$ \\
\hline Portland cement, type V & 955 \\
Silica fume $\left(18 \mathrm{~m}^{2} / \mathrm{g}\right)$ & 229 \\
Fine sand $(150-400$ microns) & 1051 \\
Precipitated silica & 10 \\
Superplasticizer (polyacrylate) & 13 \\
Steel fibres & 191 \\
Water & 153 \\
Water/binder ratio & 0.13 \\
\hline
\end{tabular}

durability [3]. Therefore, a newer material was created and utilized for both the repair and strengthening of damaged or new RC structural members, which is known as ultrahighperformance fibre-reinforced concrete (UHPFRC). Most research works highlight the two significant features of UHPFRC (durability and strength), which show promising recent outcomes, as reported by many researchers [4-8]. Studies on the mechanical properties of UHPFRC have shown that the compressive strength could be up to $163 \mathrm{MPa}$. The results have also demonstrated that increasing the percentage of steel fibres will result in increasing the flexural strength of UHPFRC [9]. Lubbers [10] investigated the behaviour of UHPFRC under compression and flexure, and it was found that the compressive and flexural strengths of UHPFRC could be 2-3 or even 6 times more than highperformance concrete (HPC), respectively.

\section{Ultrahigh-Performance Fibre-Reinforced Concrete}

UHPFRC is a highly dense, steel fibre-reinforced cementitious composite material having compressive strength in excess of $170 \mathrm{MPa}$; a tensile strength of over $8 \mathrm{MPa}$; and a flexural strength of more than $30 \mathrm{MPa}$ [11]. The high strength of UHPFRC is achieved by improving concreting techniques and materials (the addition of ultrafine pozzolans) and by having a very low water-cement ratio, high quality and higher dosages of superplasticizers, high cementitious material content, and optimum volume of highstrength ductile steel fibres. The use of steel fibres is to prevent the growth and interconnectivity of microcracks by absorbing the tensile stresses. The microcracks join together forming macrocracks [12]. A typical mix design of UHPFRC
TABle 3: UHPFRC mix design components [15].

\begin{tabular}{lc}
\hline Material & $\begin{array}{c}\text { Typical range by weight of } \\
\text { mix proportion }\left(\mathrm{kg} / \mathrm{m}^{3}\right)\end{array}$ \\
\hline Cement & $610-1080$ \\
Silica fume & $50-334$ \\
Crushed quartz & $0-410$ \\
Sand & $490-1390$ \\
S.P. & $9-71$ \\
Water & $126-261$ \\
Steel fibres & $40-250$ \\
\hline
\end{tabular}

and reactive powder concrete (RPC) (patented name Ductal $^{\circledR}$ ) is shown in Tables 1 and 2, respectively. In addition, the range of the mix of the UHPFRC used is illustrated in Table 3.

\subsection{Concept behind High Strength and Performance of UHPFRC}

(1) Low water-cement ratio: As a rule of thumb in concrete technology, the lower the water-cement ratio, the higher will be the strength. A low watercement ratio helps in reducing pore spaces and further increasing the binding between hydration products and aggregates. In order to achieve the allowable spread flow and the maximum relative density, the optimum water-binder ratio of $0.13-0.25$ was suggested in the literature. Wille et al. [16] achieved a compressive strength of $150 \mathrm{MPa}$ with a water-cement ratio, $w / c$, equal to 0.25 . In addition to the $w / c$ ratio, other strength-governing parameters are properties of the constituents, mixing procedure, mixer type, curing regime, and curing type.

(2) Ductility: The higher flexural and tensile strengths of UHPFRC are due to the addition of steel fibres. The steel fibres in the vicinity of the flexural and tensile cracks offer more efficient transfer of stresses. Thereby, reducing the crack propagation rate enhances the ductility of the material.

(3) Homogeneity: despite the low water-cement ratio, the addition of a high quantity of quality superplasticizer helps to achieve a homogenous mixture that is easy to mix and work on.

(4) Increased binder: The amount of calcium silicate $(\mathrm{C}-\mathrm{S}-\mathrm{H})$ gel (the main product of hydration) increased due to the addition of pozzolans (such as micro silica and fly ash), which react with the inert calcium hydroxide product to produce more $\mathrm{C}-\mathrm{S}-\mathrm{H}$ gel. Thereby, the density and strength of the material increased significantly. As compared to conventional concrete and HPC, relatively high fractions of cement are used in UHPFRC [17]. The compressive strength of UHPFRC increases with increasing cement content, up to a certain limit known as the optimum content. Beyond this limit, the strength has a tendency to decrease as a result of the limited contribution of the 
aggregates [18]. A mixture of less than $6 \%$ of the cement combined with the calcium aluminates is preferred due to its lower water demand. Cement content does not hydrate completely due to the lower water-binder ratio, so part of the unhydrated cement content can be replaced with silica fume, crushed quartz, or blast furnace slag without compromising the strength. Because of the much finer particle size of $0.1-10 \mu \mathrm{m}$, optimal spherical shape, and pozzolanic reactions, the gap is filled between the relatively coarser particles, and hence, the workability and compressive strength is improved [16].

(5) Aggregate: Cracking in the concrete typically begins in the proximity of the aggregates. The cementaggregate interfacial zone (ITZ) is the weakest link in normal concrete (NC). The major portion of the fracture paths in NC present along the interface between the coarse aggregate particles and the cementitious matrix is called ITZ. This may be due to the inherent weakness of ITZ or due to the stress concentration induced by the rigid aggregates embedded in the cementitious matrix. ITZ has a high $w / b$ ratio as compared with the surrounding matrix due to internal bleeding around the elongated and flat coarse aggregate particles which is characterized by the highly porous region that affects the durability of concrete. Therefore, the abovementioned weaknesses induced by ITZ can be reduced by eliminating the coarse aggregates from the mixture of UHPFRC [19]. Fine aggregates like quartz sand are used in the UHPFRC mixture and play a key role in reducing the maximum plate thickness (MPT). MPT is an important factor in the mixture design of UHPFRC. Wille et al. reported an optimum sandto-cement ratio of 1.4 for a quartz particle size of $0.8 \mathrm{~mm}[16]$.

(6) Fibres: UHPFRC exhibits ductility, and as the specimen begins to crack, the small-scale fibres reinforced the cementitious matrix causing smaller and less damaging cracks. Fibres are metallic, polymeric, or natural. Generally, metallic (steel) fibres are used for structural and nonstructural purposes. The steel fibres bridge the crack due to the strain-hardening behaviour under tensile loading of UHPFRC. The size, shape, and type of steel fibres affect the workability and energy dissipation capacity during crack bridging. For an economical and workable UHPFRC mixture, Richard and Cheyrezy recommended a $2 \%$ by mixture volume of steel fibres [20].

\subsection{Properties of UHPFRC for Effective Performance as a Repairing or Strengthening Material}

2.2.1. Tensile Strength. UHPFRC under a direct tension test has an increment in tensile strength and shows a higher strainhardening response similar to that of steel. An idealized stressstrain response of UHPFRC under direct tensile is shown in Figure 1, which shows the ductile property of UHPFRC.

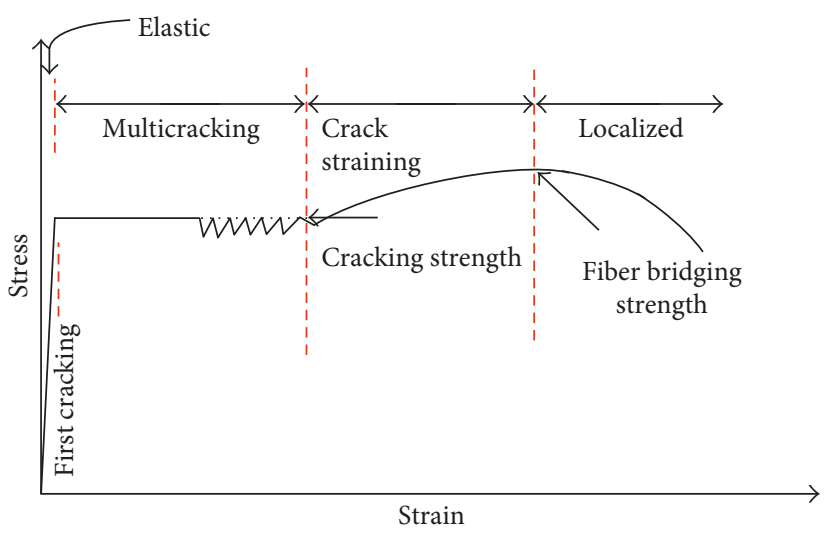

FIgURE 1: Tensile behaviour of UHPFRC under direct tensile test [6].

2.2.2. Fatigue Resistance. Tensile fatigue tests conducted by [21] on steel-reinforced UHPFRC showed that it possesses a significant amount of fatigue resistance. Therefore, UHPFRC was considered as a fatigue-strengthening material for RC structures. At the initial stage of the test, the UHPFRC material was the most active material in determining the fatigue behaviour. However, in the later stages, reinforcing bars determined the fatigue behaviour of the UHPFRC. Therefore, for high fatigue deformations, it is recommended to add reinforcing bars to the UHPFRC layer.

2.2.3. Durability Performance. The very dense microstructure of UHPFRC makes it difficult for foreign substances to penetrate it. This makes UHPFRC highly resistive to chloride penetration, sulfate attack, carbonation, etc. Experimental test results showed that UHPFRC has a high scaling, abrasion, freeze-thaw, and alkali-aggregate reaction resistance, as shown in Figure 2.

2.2.4. Coefficient of Thermal Expansion. The coefficient of thermal expansion of UHPFRC was found to be slightly higher than that of NC [7]. This is because of the coefficient of the thermal expansion of concrete which is controlled by the coefficient of its constituents, aggregate. Since the coefficient of the thermal expansion of UHPFRC and that of NC is very close, it can be suitably used as a repairing material where the differential thermal expansion between UHPFRC and the host concrete will be avoided.

2.2.5. Fire Resistance. Fire resistance tests showed that explosive spalling of UHPFRC occurs at a temperature of $790^{\circ} \mathrm{C}$, which is $100^{\circ} \mathrm{C}$ and $190^{\circ} \mathrm{C}$ more than for $\mathrm{HPC}$ and ordinary concrete (OC), respectively [22]. The compressive strength of UHPFRC increases at temperatures between 200 and $300^{\circ} \mathrm{C}$ but starts to fall above this temperature range [8]. The residual strength of UHPFRC after $60 \mathrm{~min}$ of fire test at temperatures between 450 and $550^{\circ} \mathrm{C}$ is $62.2 \%$, while for HPC and OC it is $46.7 \%$ and $58.5 \%$, respectively. Further, the loss of mass in HPC and OC was considerably more than that of UHPFRC for the same fire testing 


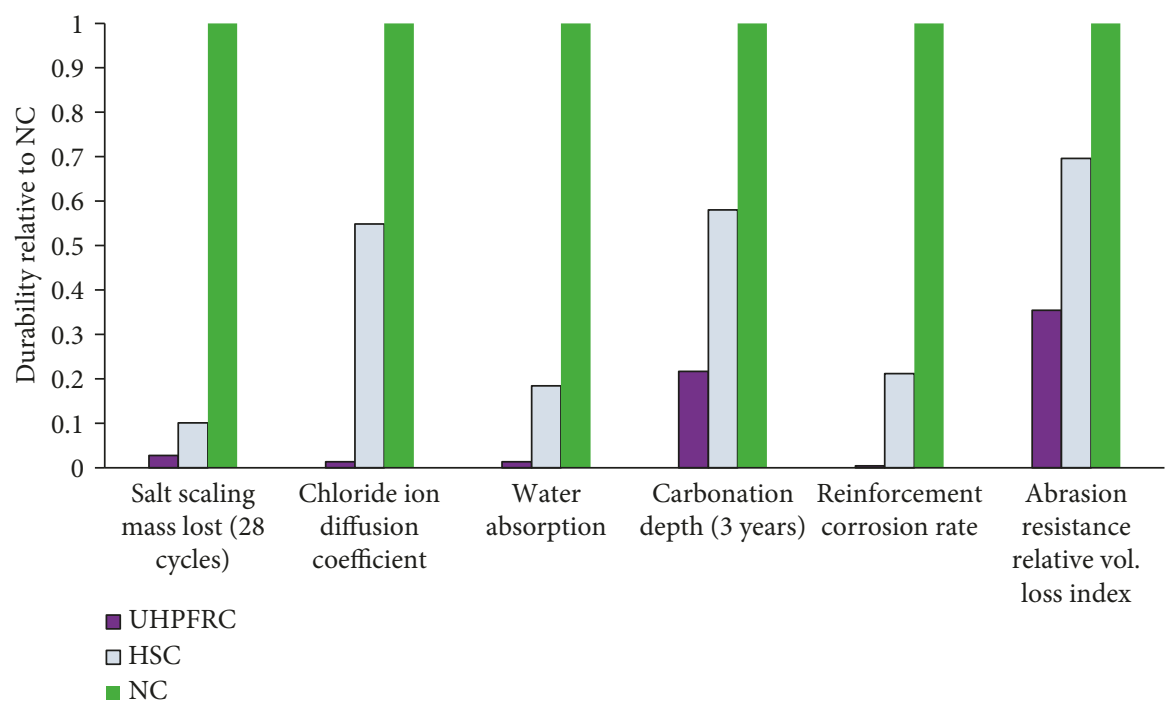

FIGURE 2: Durability performance of UHPFR relative to high-performance concrete and NC [15].

conditions [22]. As such, the high fire resistance of UHPFRC will make it a suitable repair and rehabilitation material for RC structural members.

2.3. Bond between NC and UHPFRC. Richard and Cheyrezy [20] studied the bond characteristics of UHPFRC and NC substrate surface (NCSS) by conducting different bond tests such as a slant-shear test with the bond interface inclined at $55^{\circ}, 60^{\circ}$, and $70^{\circ}$, pull off, and splitting prism tests. It was reported that the bond performance between NCSS and UHPFRC is successful. The results showed that the saturated conditions of NCSS resulted in an excellent bond performance. The roughness degree of NCSS became irrelevant to achieve a good strength of bond if the appropriate wetting conditions take place [20].

Al-Osta et al. [23] evaluated the bond strength between UHPFRC and NC by conducting bond tests such as the split cylinder tensile strength test and the slant-shear test. Epoxybonded (EP), plane surface, and sandblasted (SB) hybrid cylinder specimens were tested in the current research work. It was concluded that specimens whose NC substrate surfaces were made rough through sandblasting had a higher slant-shear strength than epoxy-bonded or plane surface specimens. In addition, failure was observed at the interface plus partial concrete substrate. The values of the split tensile strength test for both techniques (EP and SB) showed that the bond between UHPFRC and NC could be placed under excellent bond quality regardless of the surface preparation.

\section{Literature Review of Existing Studies}

Over the last decade, a large number of research studies on the repair and strengthening of concrete members using various types of high-strength and high-performance concretes have been reported. Although most of these studies were carried out for the sake of research, the outcomes of some of these studies have been put into practice and have shown promising performance.
Most of the research works were conducted to ascertain the effectiveness of these types of concrete in the repair of damaged RC members, while others were conducted on the strengthening of undamaged RC members in flexure, shear, or torsion. Others investigated the performance of normal RC-high-strength concrete composite members in which high-strength/high-performance concrete represents a large percentage of the total volume of the member.

Alaee and Karihaloo [24] studied the behaviour of retrofitted damaged RC beams with a high-performance fibrereinforced concrete known as CARDIFRC. The results indicated that the load carrying capacity of retrofitted RC beams increased for all strengthening configurations. Farhat et al. [25] studied the application and behaviour of the highperformance fibre-reinforced cementitious composite (CARDIFRC) to repair damaged beams. The experimental results indicated an increase of the failure load up to $86 \%$ with the application of CARDIFRC strips on the tension and side faces. Habel [26] studied the structural behaviour of full-scale RC beams made of UHPFRC under flexure. The tested beams were strengthened with a layer of UHPFRC on the tension side. It was noted that using a layer of UHPFRC would result in significant improvements in the structural strength of the strengthened beams. Martinola et al. [27] reported an experimental and numerical study of the effect of the fibre-reinforced concrete repair or strengthening of full-scale RC beams. The results indicated the viability of the recommended technique in both the ultimate and serviceability stages. Mostosi et al. [28] evaluated the increment in the bearing capacity of the RC members under shear action, which is one of the challenging issues in the files of structural concrete repair. Concrete beams containing only longitudinal reinforcement bars were strengthened with highperformance fibre-reinforced concrete (HPFRC) jackets incorporating U-bent wire mesh. Experimental results showed that the thickness of the jacket has an impact on the maximum load capacity, while the HPFRC jacket effectively played the role of lacking shear reinforcement. A new 
UHPFRC-NC hybrid floor system without steel-reinforcing bars was developed by Hakeem [9]. The idea is to utilise the tensile strength of steel fibres in UHPFRC instead of using reinforcing bars. The techniques applied to three different systems: (i) the UHPFRC layer at the top and bottom, (ii) the UHPFRC layer at the top and bottom of hollow core slabs, and (iii) slabs reinforced with precast with UHPFRCdeformed bars. Test results showed promising outcomes and potential that the technique could be suitably utilized in designing precast floors for light-to-medium loaded buildings. Moreover, the technique will have more applications in corrosive environments where the $\mathrm{RC}$ members face high risks of corrosion. A combined system of UHPFRC-CFRP was used by Garner [29] to strengthen RC slabs. The CFRP was applied after scraping the slab top surface to a certain depth, and the UHPFRC was cast over the CFRP. The idea of using UHPFRC was to shift the neutral axis position of the slab and place the CFRP laminate under tension. Test results indicated significant increases in the load carrying capacity and stiffness of the strengthened RC slabs. The same technique was used by Genedy [30] to strengthen RC T-beams. The UHPFRC-CFRP system was applied to the top of the T-beams using the same technique by Garner [29]. Test results showed a much lower increase in the load bearing capacity and stiffness compared to what was obtained in the RC slabs by Garner [29]. Hassanean et al. [31] investigated the flexural behaviour of $2.3 \mathrm{~m}$ long beams strengthened and retrofitted using the mixed steel fibre concrete jacket (MSFCJ) under a short-time repeated load in a three-point load configuration. The experimental results indicated a significant increase in stiffness and a reduction in the number of cracks, which were concentrated in the middle third portion of the strengthened beams. This indicated prevention of the formation of shear cracks. Noshiravani and Brühwiler [32] conducted an experimental study to investigate the effect of UHPFRC as an additional tensile reinforcement on a cantilever-reinforced concrete beam. It was observed that most of the beams fail in flexure at a force 2- 2.8 times higher than the reference (control) RC beam. It was noticed that there was an improvement in the deformation capacity of the member. Iskhakov et al. [33] studied experimentally the behaviour of a composite concrete beam made up of NC on the compression side and steel fibre-reinforced concrete on the tension side. The results showed that the failure load and ductility of the strengthened beam with the abovementioned configuration increased more as compared to other strengthening techniques using the same material. Mahmud et al. [34] investigated the size effects of UHPFRC on the flexural strength of the beams. A total of fifteen beams with different depths were tested. Mahmud et al. also developed a numerical model using the ABAQUS software. Both the experimental and numerical results showed that the size effect in the flexural strength of the beams is almost negligible. Ruano et al. [35] evaluated the structural performance of using steel fibre-reinforced concrete (SFRC) in the shear retrofitting of the RC beams. In order to evaluate the contribution of the fibre content, different dosages of fibre were used $\left(30 \mathrm{~kg} / \mathrm{m}^{3}\right.$ and $\left.60 \mathrm{~kg} / \mathrm{m}^{3}\right)$. The experimental results proved that the presence of fibres prevents debonding and generally enhances the overall integrity of the beams. In addition, the efficiency of the SFRC for shear strengthening is directly related to the use of steel stirrups. Chalioris et al. [36] investigated the use of thin reinforced self-compacting concrete (SCC) for strengthening of conventional shear-critical RC beams through experimental and analytical studies. The strengthened beams exhibited increased strength and ductility in addition to favourable failure behaviours. It was concluded that the reinforced SCC may be considered as a quick option for strengthening the existing RC beams. Bastien Masse and Brühwiler [37] investigated a retrofitting technique of a bridge deck slab using ultrahighperformance fibre-reinforced concrete (UHPFRC). It was concluded that a layer of UHPFRC over an RC section significantly increases the load bearing capacity. Ombres [38] studied that the behaviour of RC beams strengthened in shear with fabric-reinforced cementitious matrix (FRCM) with varying configurations of FRCM strips (U-wrapped continuous and discontinuous). The results showed that the FRCM strengthening method increased the shear capacity of the RC beam when an adequate strengthening configuration was adopted. Hussein and Amleh [39] investigated the shear strength of the composite beams made up of normal strength concrete and UHPFRC. The tested beams had a high-grade NC layer in the compression zone and an UHPFRC layer on the tension side. The experimental results indicated good enhancements in the flexural and shear capacities of the developed composite beams. Ruano et al. [40] carried out an experimental work and a numerical modelling of the behaviour of RC beams strengthened in shear with high-performance selfcompacting concrete. The experimental program involved 14 RC beams where some of them were damaged and repaired, while the rest were initially strengthened. Both the experimental and numerical results demonstrated that the fibre content not only prevents debonding from the concrete substrate but also increases the load bearing capacity of the strengthened RC beams. Prem et al. [41] studied experimentally the performance of retrofitted or repaired predamaged RC beams with a layer of UHPFRC at the tension side. The results indicated that using UHPFRC, as repaired materials for the predamaged RC beams, would result in a significant increase in the failure load. Lampropoulos et al. [13] demonstrated that using a layer of UHPFRC at different locations, as strengthened materials of RC beams, could increase the ultimate flexural strength of all of the strengthened beams. Mohammed et al. [3] tested many RC beam specimens strengthened with UHPFRC under torsional loading. The beams had no stirrups. The results indicated that strengthening the beams on all four sides increased the torsional strength. Iqbal et al. [42] examined the use of steel fibre-reinforced high-strength lightweight selfcompacting concrete (SHLSCC) for the strengthening of RC beams. An analytical model was developed to predict the bending moment capacities of such strengthening techniques. It was stated that the SHLSCC method is an effective technique to strengthen the flexural members. The experimental results showed that the improvement in strength is dependent on the thickness of the strengthening layer (SHLSCC layer) in the tension zone. Al-Osta et al. [23] investigated the flexural behaviour of RC beams retrofitted with UHPFRC. Two different 
techniques for the strengthening of RC beams using UHPFRC with different configurations were assessed in this research. The two techniques are as follows: (i) the NC surface was made rough by sandblasting and in situ casting of UHPFRC around beams with different configurations, and (ii) an epoxy primer was used to attach the precast UHPFRC plates with conventional RC beams. It was found that there was no considerable difference in the results of the two strengthening techniques. However, the sandblasting interface preparation technique was more promising. It was reported that the stiffness and cracking load of the strengthened beams were increased, crack propagation was delayed, and cracks were concentrated in the middle third portion of the beam, which reflected the increment in the shear strength of the beam.

\section{Analysis and Discussion of Results from the Review}

4.1. Effect of Strengthening RC Beams with UHPFRC on Ultimate Load Capacity. Results have shown that strengthening with UHPFRC increases the ultimate load capacity of both damaged and undamaged RC beams up to 1.99 and 2.77 times that of the control, respectively, depending on the tensile strength of the UHPFRC used. Figure 3 shows the available maximum increase in failure loads achieved by strengthening with UHPFRC.

4.2. Effect of Strengthening Configuration. The strengthening configuration was found to have a significant effect on the strengthened beam specimens. The results showed that beams strengthened at the three sides (bottom + two longitudinal sides) depicted the highest increment in moment capacity, as compared to strengthening at the top and bottom on the longitudinal sides only (Figure 4 ). However, strengthening at the bottom or top showed the lowest values for moment capacity.

The torsion strength test conducted by Mohammed et al. [3] on RC beams, which were strengthened with UHPFRC jacketing using different strengthening configurations, showed varying cracking and ultimate torque enhancement. Furthermore, beams were strengthened at all four sides showing the highest level of enhancement, as clearly illustrated in Figure 5.

\subsection{Effect of UHPFRC Layer Thickness on Ultimate Load} Increase. Studies have shown that the failure load of the strengthened RC beam specimen increases as the thickness of the UHPFRC layers increases for the same configuration arrangement, as shown in Figure 6.

Figure 6(b) shows beams strengthened with UHPFRC at the tension side with varying degrees of thickness in the UHPFRC layer: $30 \mathrm{~mm}$ (NR3), $50 \mathrm{~mm}$ (NR5), and $100 \mathrm{~mm}$ (NR10) [26]. It can be observed that the ultimate load increases as the UHPFRC layer increases. However, a change of behaviour and sudden failure were observed as the layer became thicker (NR10). This indicates that the failure of the UHPFRC jacket was followed by a softening behaviour up to a load level equal to the yield load of the steel reinforcement

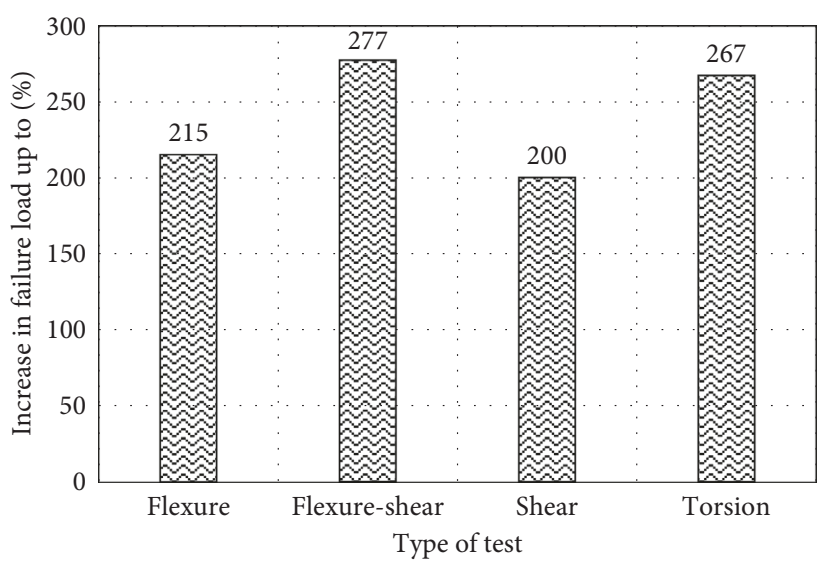

FIgURE 3: Percentage increase in failure load of strengthened RC beams under different tests $[3,13,39]$.

inside the concrete beam. Then, the steel is activated, and the load stabilises with the behaviour becoming more ductile. Also, Figure 7 shows that increasing the layer thickness of UHPFRC increases the torsional load of the RC beams as proved by Mohammed [3].

4.4. Effect of Curing Type on Capacity Enhancement. The type of curing (for which UHPFRC-strengthened RC beams were subjected) was found to affect the ultimate load of the strengthened beams. Beam specimens were cured using hot air curing, which shows the highest values in the failure load. Damaged RC beams strengthened with UHPFRC and cured using different curing methods were studied by Prem et al. [41], as shown in Figure 8.

4.5. Effect of Fibre Content on Flexural Capacity, Stiffness, and Shear Capacity of RC Beams. From the reviewed studies, it was observed that an increase in the steel fibre content in the UHPFRC jacket increases both the flexural capacity and the stiffness of the strengthened beams for the same strengthening configuration (Figure 9). On the other hand, the variation of steel fibres in both the UHPFRC-normal strength concrete (NSC) composite beam and the UHPFRC-high-strength concrete (HSC) composite beams [39] showed that the variation of steel fibre content on the shear capacity of the composite beams is insignificant.

4.6. Effect of Addition of Reinforcing Bars inside UHPFRC Layer. The addition of a steel-reinforcing bar in the UHPFRC jacket was found to be significant to improve the ultimate load and stiffness of the strengthened member. The reinforcing bars in the UHPFRC layer serves as a macro fibre contained in the UHPFRC. In other words, the crack width becomes larger, and the steel fibres are pulled out. The reinforcing bars take over the tensile force over the macrocracks until the steel yielded and failed, hence increasing both the capacity and ductility of the member. A study on this effect was carried out by Ahlborn et al. [7] and Brühwiler [43], and the load-deflection curves are shown in Figure 10. 


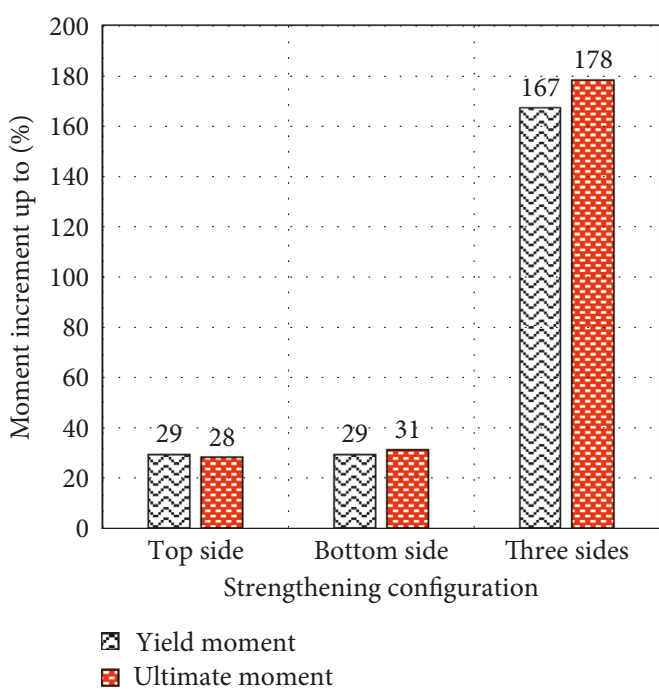

(a)

FIGURE 4: Effect of strengthening configuration on

The strange/unusual behaviour shown by NR10 was due to high thickness of the UHPFRC layer as discussed in Section 4.3.

4.7. Effect of UHPFRC-CFRP Composite Strengthening. Using UHPFRC and CFRP to strengthen RC members in a systematic manner similar to that conducted by Garner [29] and Genedy [30] has proven effective, particularly for thin members such as slabs. The arrangement is such that the CFRP laminate provides additional tensile strength to the member, while the UHPFRC provides additional compressive strength. A typical arrangement of the system is shown in Figure 11.

Results show that this technique is not suitable for deep members such as beams because of the problem of placing the CFRP below the neutral axis. For this technique to be effective, the buried CFRP laminate needs to be placed completely in tension, which is easier to achieve in thinner members such as slabs. The results of tests conducted using this technique on RC slabs and T-beams are presented and compared in Table 4.

However, the effectiveness of this technique is affected by the compressive strength, as well as the thickness of the UHPFRC layer applied at the top of the member.

4.8. Cost Comparison with Other Strengthening Techniques. A strengthening cost comparison between UHPFRC and various other methods used to strengthen RC beams is presented in Figure 12 and Table 5 based on the average price of materials in Saudi Arabia. The results showed that UHPFRC has a higher cost to achieve an increase in the capacity up to $88 \%$ compared to strengthening with reinforced concrete (RC) and reinforced self-compacting concrete (RSCC). However, due to the durability property of UHPFRC compared to these two materials, the overall service life cost of strengthening with UHPFRC will be lower because UHPFRC will incur a lower maintenance cost [43].

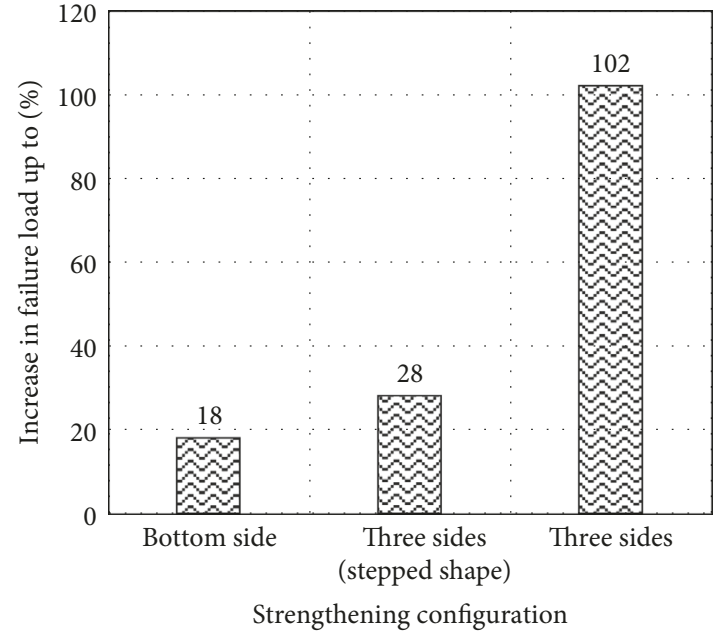

(b)

(a) flexural capacity [13] and (b) shear capacity [24].

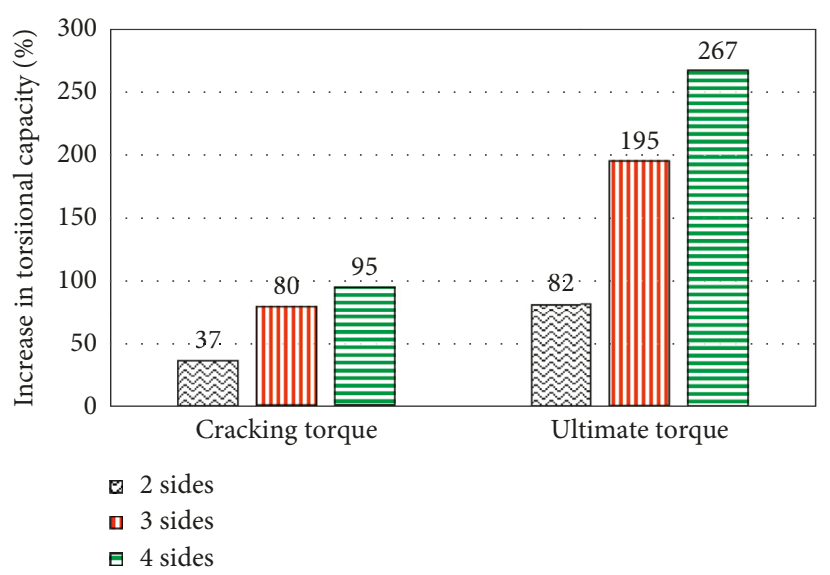

FIGURE 5: Effect of strengthening configuration on torsional capacity of strengthened RC beams [3].

\section{Conclusions}

From the study conducted, the following conclusions are drawn:

(1) The use of UHPFRC in the repairing and strengthening of RC structural members increases the ultimate load and stiffness, as well as reducing the crack width of the member.

(2) Hot air curing of the strengthened members compared to other curing methods showed the highest values in the failure load.

(3) There is a high bond strength between UHPFRC and the host concrete member regardless of the surface preparation. However, applying the sandblasting technique on the parent concrete surface before strengthening gives the highest strength. 


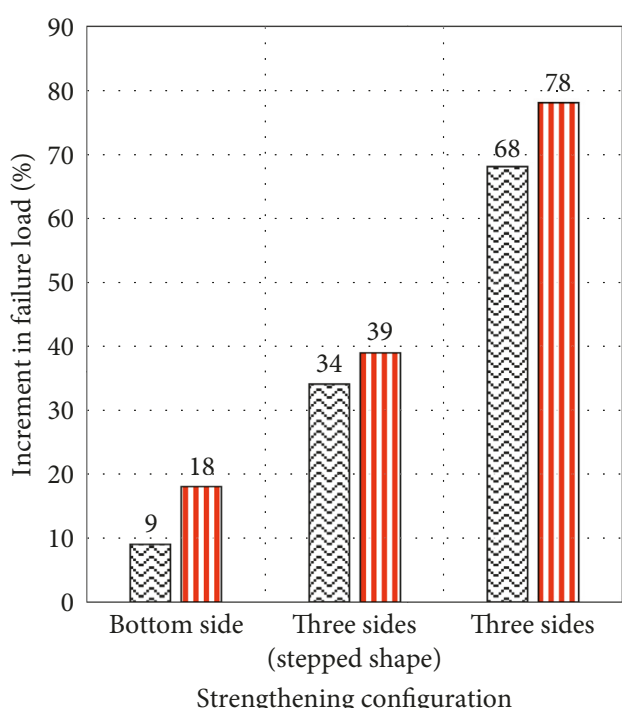

$16 \mathrm{~mm}$ ㅁ. $20 \mathrm{~mm}$

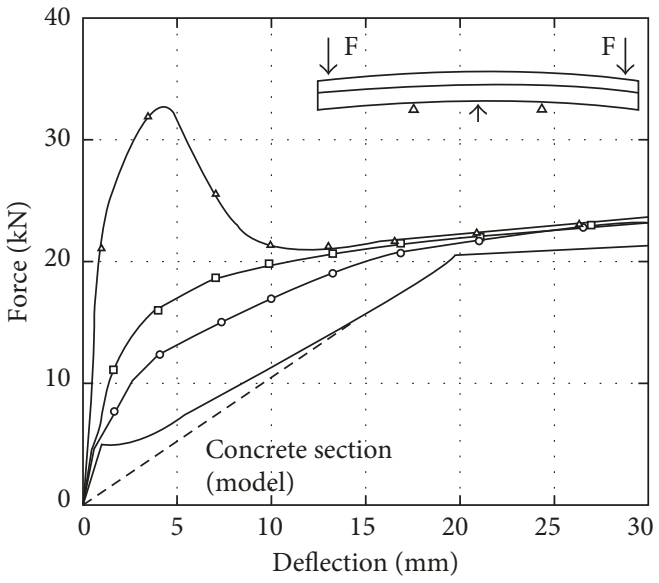

$\multimap$ NR3

$\rightarrow-N R 5$

$\rightarrow$ NR10

(a)

(b)

FIgURE 6: Effect of UHPFRC layer thickness on (a) ultimate load [24] and (b) load-deflection behaviour [26].

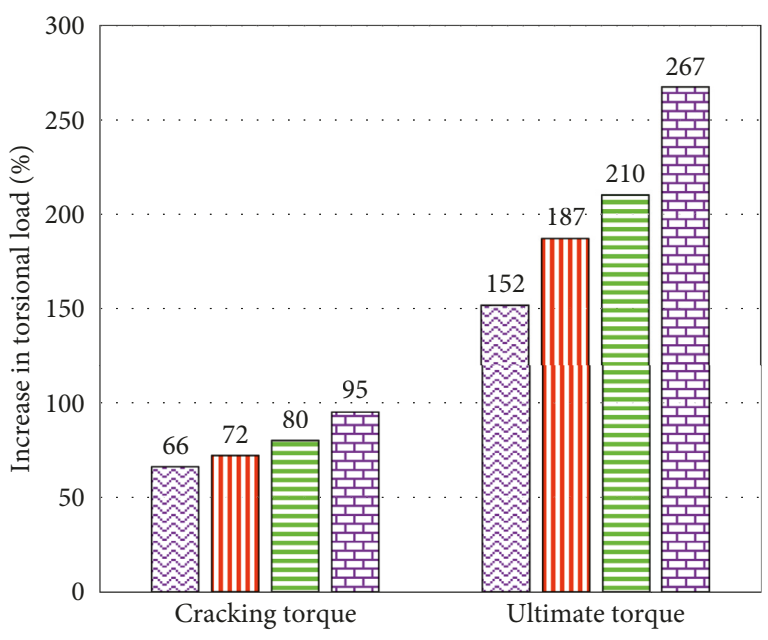

ㅁ $10 \mathrm{~mm}$

प $15 \mathrm{~mm}$

ㅁ $20 \mathrm{~mm}$

Б $25 \mathrm{~mm}$

FIGURE 7: Effect of UHPFRC layer thickness on torsion capacity of RC beams [3].

(4) The behaviour of the strengthened member depends on the strengthening configuration. Members strengthened on all sides show a monolithic behaviour while members strengthened on selected sides might show debonding at high loads.

(5) RC members strengthened on all sides showed the highest increase in load capacity and stiffness.

(6) The thickness of the UHPFRC layer used to repair or strengthen RC members has a direct influence on

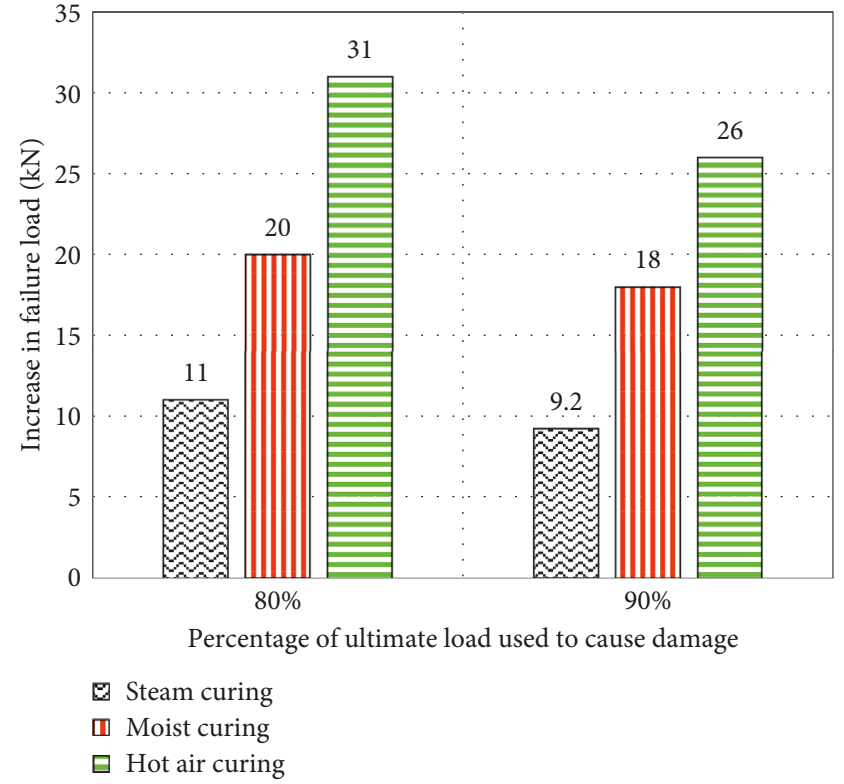

FIGURE 8: Effect of curing type on load capacity of strengthened damaged RC beams [41].

the capacity enhancement of the member. An increase in the thickness of the UHPFRC layer increases both the load capacity and the stiffness of the strengthened member.

(7) The behaviour of the RC beams strengthened with thick layers of UHPFRC showed sudden failure after reaching the ultimate load.

(8) The addition of reinforcing bars at the UHPFRC layer increases the hardening and the ultimate resistance of the strengthened member. 


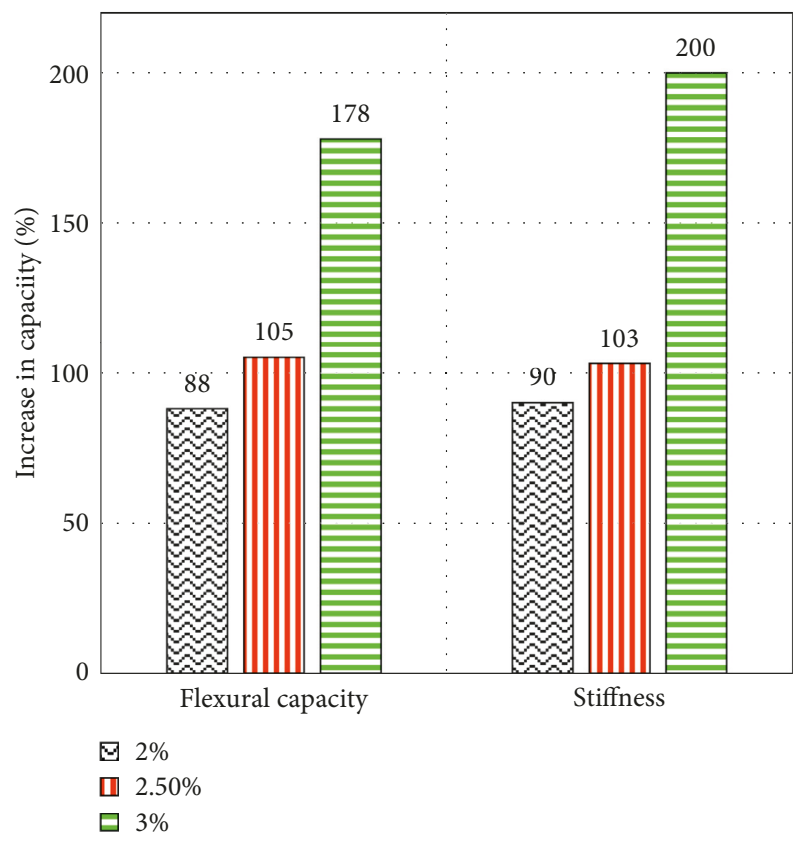

(a)

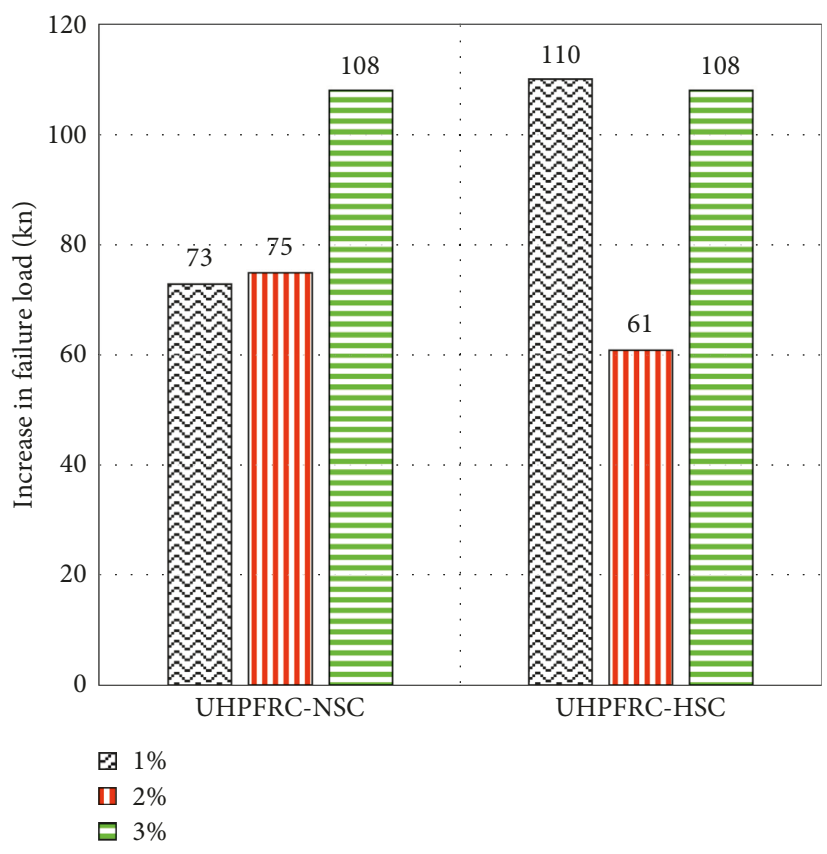

(b)

Figure 9: Effect of steel fibre content on (a) flexural capacity and stiffness of strengthened RC beams [13, 23, 27] and (b) shear capacity [39].

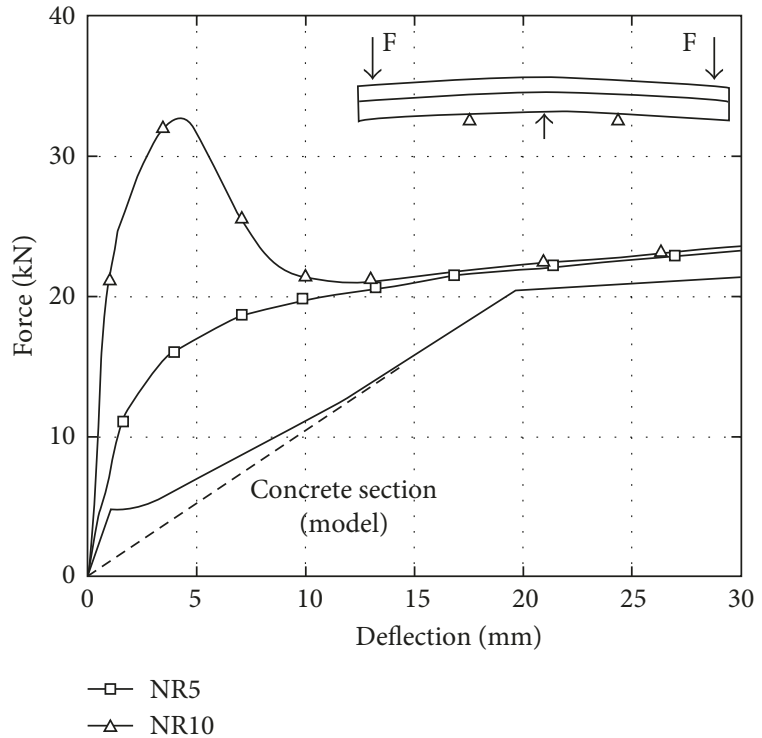

(a)

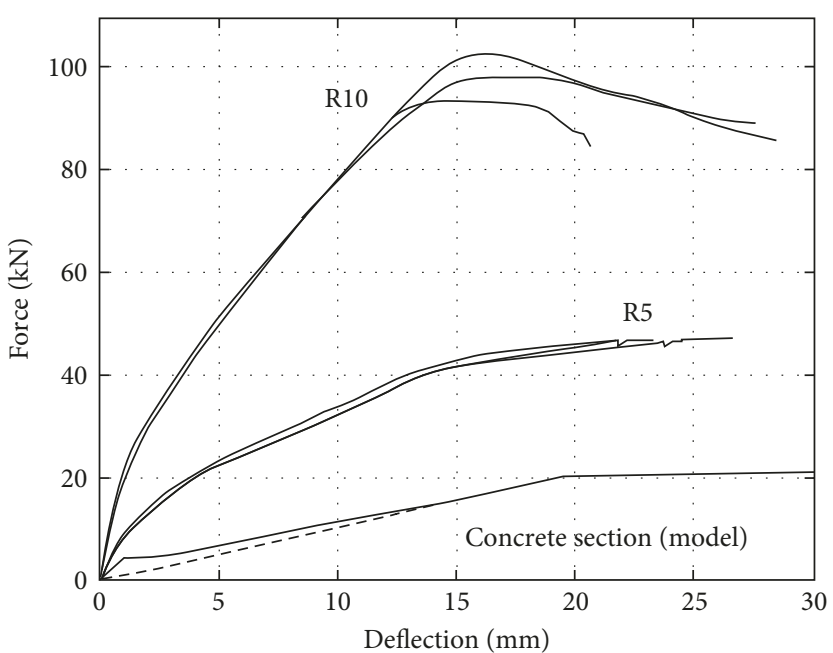

(b)

FIGURE 10: Load-deflection behaviour of RC with UHPFRC layer. (a) Without reinforcing bars (NR). (b) With reinforcing bar (R) [26].

(9) Strengthening with UHPFRC gives lower overall service life compared to strengthening with other materials, that is, due to the high durability property of UHPFRC.

(10) Increasing the steel fibre content in UHPFRC increases the flexural strength of the strengthened member while the variation of steel fibre content does not significantly affect the shear capacity of the strengthened member.
(11) Analytical models based on the flexure theory of RC beams can be suitably used to predict the behaviour of RC beams strengthened with UHPFRC.

\section{Recommendations for Future Studies}

The following recommendations are suggested for better understanding of the potential of UHPFRC in repairing and strengthening, as well as the behaviours of the 


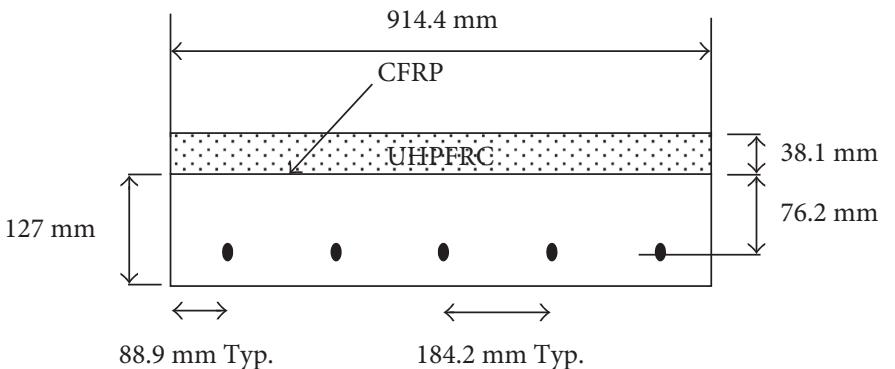

(a)

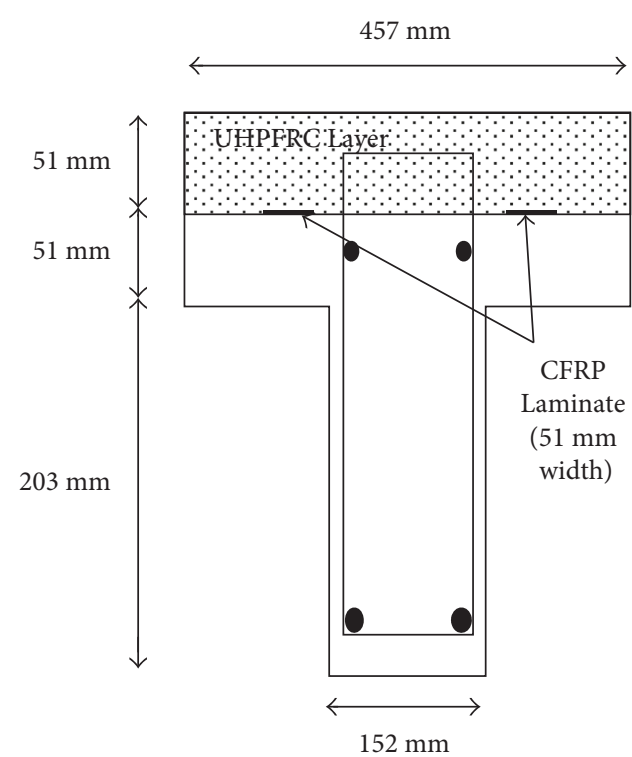

(b)

FIgURE 11: Cross section of UHPFRC-CFRP composite strengthening of (a) RC slab [29] and (b) RC T-beam [30].

TABle 4: Properties of RC T-beam and slab strengthened by UHPFRC-CFRP system [29, 30].

\begin{tabular}{lcccc}
\hline Specimen & Increase stiffness (\%) & Cause of failure & Failure mode & Increase in capacity (\%) \\
\hline Control beam & - & Crushing at top & Flexure & - \\
UHPFRC-CFRP beam & 15 & Debonding & Shear & 9.2 \\
Control slab & - & Crushing at top & Flexure & - \\
UHPFRC-CFRP slab & 197 & Debonding & Flexure & 41 \\
\hline
\end{tabular}

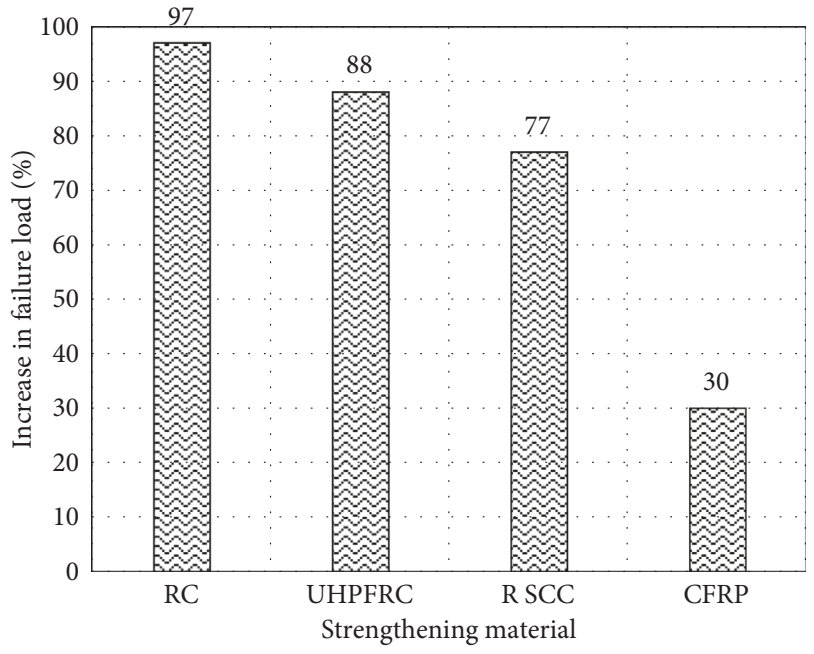

FIGURE 12: Comparison of increase failure load of RC beam strength using different materials [13, 36, 44, 45].

strengthened members under various loading and environmental conditions:

(1) Most of the studies were conducted on RC beam elements. There is a need for investigations on other structural elements, particularly columns and walls.
TABle 5: Cost comparison of different strengthening materials to achieve the given capacity enhancement.

\begin{tabular}{lc}
\hline Material & Cost to achieve strengthening (\$) \\
\hline RC & 3.9 \\
UHPFRC & 11.3 \\
R SCC & 4.6 \\
CFRP & 7.3 \\
\hline
\end{tabular}

(2) In addition, most of the research works were conducted on undamaged structural members. There is a need for more research on strengthening damaged members, which is the main purpose of repair and strengthening.

(3) There is a need to develop closed form design equations for flexural, shear, and torsional strengthening of the structural members with UHPFRC. In addition, the development of design guidelines is needed if the material is to be adopted in practice.

(4) The performance of the strengthened concrete members under various loading conditions such as fatigue or cyclic loading, fire load, and seismic and impact loads should be investigated with more emphasis given to the interface condition between $\mathrm{NC}$ and UHPFRC. 
(5) Most or all the works reviewed here have been conducted under one environmental condition. There is a need to check performance (particularly the interface condition) under varying environmental conditions such as freezing and thawing, and wetting and drying.

(6) In addition, the durability performance of strengthened RC members against chemical attack such as chloride and acid attacks should be investigated with emphasis given to the density and thickness of the UHPFRC layer to provide the required protection against penetration by such substances.

\section{Conflicts of Interest}

The author declares that there are no conflicts of interest regarding the publication of this paper.

\section{Acknowledgments}

The author would like to acknowledge the support provided by the Deanship of Scientific Research (DSR) at King Fahd University of Petroleum \& Minerals (KFUPM), Dhahran, Saudi Arabia, for funding this work through Project no. IN161055. The support provided by the Department of Civil and Environmental Engineering is also acknowledged.

\section{References}

[1] H. A. El-Enein, H. Azimi, K. Sennah, and F. Ghrib, "Flexural strengthening of reinforced concrete slab-column connection using CFRP sheets," Construction and Building Materials, vol. 57, pp. 126-137, 2014.

[2] G. Monti and M. Liotta, "FRP-strengthening in shear: tests and design equations," in Proceedings of the 7th International Symposium on Fiber-Reinforced Polymer (FRP) Reinforcement for Concrete Structures, Kansas City, Missouri, November 2005.

[3] T. J. Mohammed, B. A. Bakar, and N. M. Bunnori, "Torsional improvement of reinforced concrete beams using ultra highperformance fiber reinforced concrete (UHPFC) jacketsexperimental study," Construction and Building Materials, vol. 106, pp. 533-542, 2016.

[4] S. Rahman, T. Molyneaux, and I. Patnaikuni, "Ultra high performance concrete: recent applications and research," Australian Journal of Civil Engineering, vol. 2, no. 1, pp. 13-20, 2005.

[5] B. A. Graybeal, Material Property Characterization of UltraHigh Performance Concrete, FHWA-HRT-06-103, McLean, VA, USA, 2006.

[6] B. A. Graybeal and F. Baby, "Development of direct tension test method for ultra-high-performance fiber-reinforced concrete," ACI Materials Journal, vol. 110, no. 2, 2013.

[7] T. Ahlborn and D. K. Harris, "Strength and durability characterization of ultra-high performance concrete under variable curing conditions," in Transportation Research Board Annual Meeting, vol. 22, no. 51, pp. 68-75, 2011.

[8] Y.-S. Tai, H.-H. Pan, and Y.-N. Kung, "Mechanical properties of steel fiber reinforced reactive powder concrete following exposure to high temperature reaching $800^{\circ} \mathrm{C}$," Nuclear Engineering and Design, vol. 241, no. 7, pp. 2416-2424, 2011.
[9] I. Y. A. Hakeem, Characterization of an Ultra-High Performance Concrete, King Fahd University of Petroleum and Minerals, Saudi Arabia, 2011.

[10] A. R. Lubbers, Bond Performance Between Ultra-High Performance Concrete and Prestressing Strands, Ohio University, Athens, OH USA, 2003.

[11] B. A. Tayeh, B. H. Abu Bakar, M. A. Megat Johari, and Y. Lei Voo, "Utilization of ultra-high performance fibre concrete (UHPFC) for rehabilitation-a review," Procedia Engineering, vol. 54, pp. 525-538, 2013.

[12] M. Schmidt and E. Fehling, "Ultra-high-performance concrete: research, development and application in Europe," ACI Special Publication, vol. 228, pp. 51-78, 2005.

[13] A. Lampropoulos, S. A. Paschalis, O. T. Tsioulou, and S. E. Dritsos, "Strengthening of reinforced concrete beams using ultra high performance fibre reinforced concrete (UHPFRC)," Engineering Structures, vol. 106, pp. 370-384, 2016.

[14] P. Richard and M. H. Cheyrezy, "Reactive powder concretes with high ductility and 200-800 MPa compressive strength," Special Publication, vol. 144, pp. 507-518, 1994.

[15] T. L. V. Voort, Design and Field Testing of Tapered H-Shaped Ultra High Performance Concrete Piles, M.S. thesis, Iowa State University, Ames, Iowa, 2008.

[16] K. Wille, A. E. Naaman, and G. J. Parra-Montesinos, "Ultrahigh performance concrete with compressive strength exceeding $150 \mathrm{MPa}$ (22 ksi): a simpler way," ACI Materials Journal, vol. 108, no. 1, pp. 46-54, 2011.

[17] E. Ghafari, M. Arezoumandi, H. Costa, and E. Júlio, "Influence of nano-silica addition on durability of UHPC," Construction and Building Materials, vol. 94, pp. 181-188, 2015.

[18] I. Talebinejad, B. Seyed Asadollah, I. Amirhossein, and S. Mohammad, "Optimizing mix proportions of normal weight reactive powder concrete with strengths of 200-350 $\mathrm{MPa}$," in Proceedings of the Ultra High Performance Concrete (UHPC), International Symposium on Ultra High Performance Concrete, Kassel, Germany, September 2004.

[19] J. J. Park, S. T. Kang, K. T. Koh, and S. W. Kim, "Influence of the ingredients on the compressive strength of UHPC as a fundamental study to optimize the mixing proportion," in Proceedings of the International Symposium on Ultra-High Performance Concrete, Structural Materials and Engineering Series, Kassel, Germany, March 2008.

[20] P. Richard and M. Cheyrezy, "Composition of reactive powder concretes," Cement and Concrete Research, vol. 25, no. 7, pp. 1501-1511, 1995.

[21] T. Makita and E. Brühwiler, "Tensile fatigue behaviour of Ultra-High Performance Fibre Reinforced Concrete combined with steel rebars (R-UHPFRC)," International Journal of Fatigue, vol. 59, pp. 145-152, 2014.

[22] C.-T. Liu and J.-S. Huang, "Fire performance of highly flowable reactive powder concrete," Construction and Building Materials, vol. 23, no. 5, pp. 2072-2079, 2009.

[23] M. A. Al-Osta, M. N. Isa, M. H. Baluch, and M. K. Rahman, "Flexural behavior of reinforced concrete beams strengthened with ultra-high performance fiber reinforced concrete," Construction and Building Materials, vol. 134, pp. 279-296, 2017.

[24] F. J. Alaee and B. L. Karihaloo, "Retrofitting of reinforced concrete beams with CARDIFRC," Journal of Composites for Construction, vol. 7, no. 3, pp. 174-186, 2003.

[25] F. Farhat, D. Nicolaides, A. Kanellopoulos, and B. L. Karihaloo, "High performance fibre-reinforced cementitious composite (CARDIFRC)-performance and application to retrofitting," 
Engineering Fracture Mechanics, vol. 74, no. 1-2, pp. 151-167, 2007.

[26] K. Habel, Structural Behaviour of Elements Combining UltraHigh Performance Fibre Reinforced Concretes (UHPFRC) and Reinforced Concrete, Ph.D. thesis no. 3036, Swiss Federal Institute of Technology, Lausanne, Switzerland, 2004.

[27] G. Martinola, A. Meda, G. A. Plizzari, and Z. Rinaldi, "Strengthening and repair of RC beams with fiber reinforced concrete," Cement and Concrete Composites, vol. 32, no. 9, pp. 731-739, 2010.

[28] S. Mostosi, A. Meda, P. Riva, and S. Maringoni, "Shear strengthening of RC beams with high performance jacket," in Proceedings of the fib Symposium 2011 in Prague: Concrete engineering for excellence and efficiency, Prague, Czech Republic, September 2011.

[29] A. P. Garner, Strengthening Reinforced Concrete Slabs Using a Combination of CFRP and UHPC, M.S. thesis, UNM Digital Repository, Albuquerque, NM, USA, 2011.

[30] M. Genedy, A New CFRP-UHPC System for Strengthening Reinforced Concrete T-Beams, M.S. thesis, UNM Digital Repository, Albuquerque, NM, USA, 2014.

[31] Y. A. Hassanean, K. Abas Assaf, S. E. Abdel Raheem, and A. N. M. Arafa, "Flexural behavior of strengthened and repaired RC beams by using steel fiber concrete jacket under repeated load," International Journal of Civil and Structural Engineering, vol. 3, no. 3, pp. 564-578, 2013.

[32] T. Noshiravani and E. Brühwiler, "Experimental investigation on reinforced ultra-high-performance fiber-reinforced concrete composite beams subjected to combined bending and shear," ACI Structural Journal, vol. 110, no. 2, p. 251, 2013.

[33] I. Iskhakov, Y. Ribakov, K. Holschemacher, and T. Mueller, "High performance repairing of reinforced concrete structures," Materials \& Design, vol. 44, pp. 216-222, 2013.

[34] G. H. Mahmud, Z. Yang, and A. M. Hassan, "Experimental and numerical studies of size effects of Ultra High Performance Steel Fibre Reinforced Concrete (UHPFRC) beams," Construction and Building Materials, vol. 48, pp. 1027-1034, 2013.

[35] G. Ruano, F. Isla, R. I. Pedraza, D. Sfer, and B. Luccioni, "Shear retrofitting of reinforced concrete beams with steel fiber reinforced concrete," Construction and Building Materials, vol. 54, pp. 646-658, 2014.

[36] C. E. Chalioris, G. E. Thermou, and S. J. Pantazopoulou, "Behaviour of rehabilitated RC beams with self-compacting concrete jacketing-analytical model and test results," Construction and Building Materials, vol. 55, pp. 257-273, 2014.

[37] M. Bastien Masse and E. Brühwiler, "Ultra high performance fiber reinforced concrete for strengthening and protecting bridge deck slabs," in Bridge Maintenance, Safety, Management And Life Extension, CRC Press-Taylor \& Francis Group, Boca Raton, FL, USA, 2014.

[38] L. Ombres, "Structural performances of reinforced concrete beams strengthened in shear with a cement based fiber composite material," Composite Structures, vol. 122, pp. 316$329,2015$.

[39] L. Hussein and L. Amleh, "Structural behavior of ultra-high performance fiber reinforced concrete-normal strength concrete or high strength concrete composite members," Construction and Building Materials, vol. 93, pp. 1105-1116, 2015.

[40] G. Ruano, F. Isla, D. Sfer, and B. Luccioni, "Numerical modeling of reinforced concrete beams repaired and strengthened with SFRC," Engineering Structures, vol. 86, pp. 168-181, 2015.
[41] P. R. Prem, A. R. Murthy, G. Ramesh, B. H. Bharatkumar, and N. R. Iyer, "Flexural behaviour of damaged RC beams strengthened with ultra high performance concrete," in Advances in Structural Engineering, Springer, Berlin, Germany, 2015.

[42] S. Iqbal, A. Ali, K. Holschemacher, T. A. Bier, and A. A. Shah, "Strengthening of RC beams using steel fiber reinforced high strength lightweight self-compacting concrete (SHLSCC) and their strength predictions," Materials \& Design, vol. 100, pp. 37-46, 2016.

[43] E. Brühwiler, "Rehabilitation and strengthening of concrete structures using ultra-high performance fibre reinforced concrete," in Proceedings of Concrete Repair, Rehabilitation and Retrofitting III: 3 rd International Conference on Concrete Repair, Rehabilitation and Retrofitting, ICCRRR-3, pp. 3-5, CRC Press, Cape Town, South Africa, September 2012.

[44] M. N. Isa, Experimental Investigation into the Flexural Behaviour of UHPFRC Strengthened RC Beams, King Fahd University of Petroleum and Minerals, Dhahran, Saudi Arabia, 2016.

[45] I. Jankowiak, "Analysis of RC beams strengthened by CFRP strips-experimental and FEA study," Archives of Civil and Mechanical Engineering, vol. 12, no. 3, pp. 376-388, 2012. 


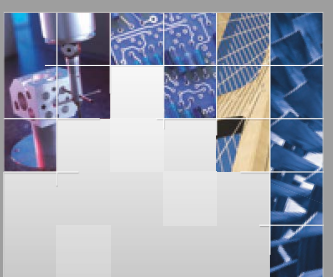

\section{Enfincering}
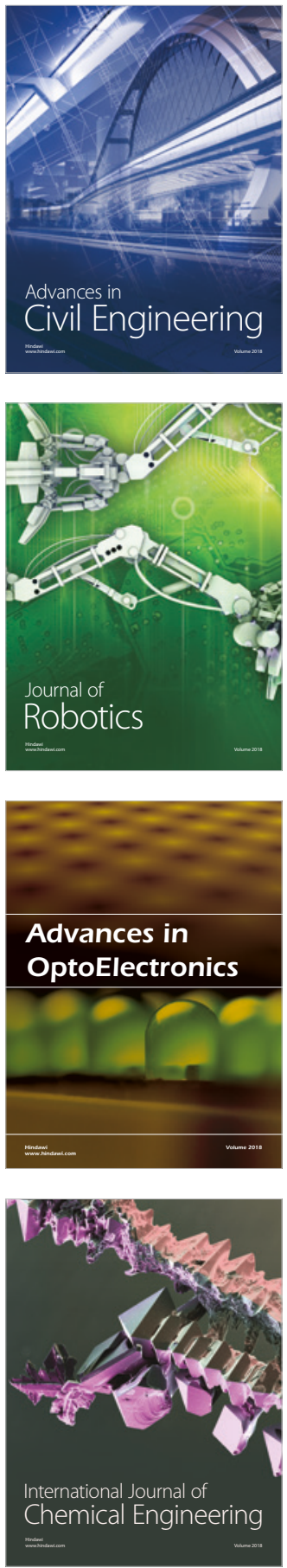

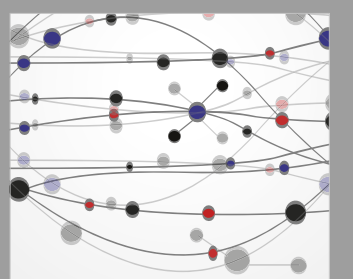

\section{Rotating \\ Machinery}

The Scientific World Journal

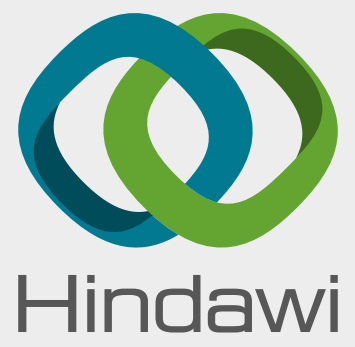

Submit your manuscripts at

www.hindawi.com
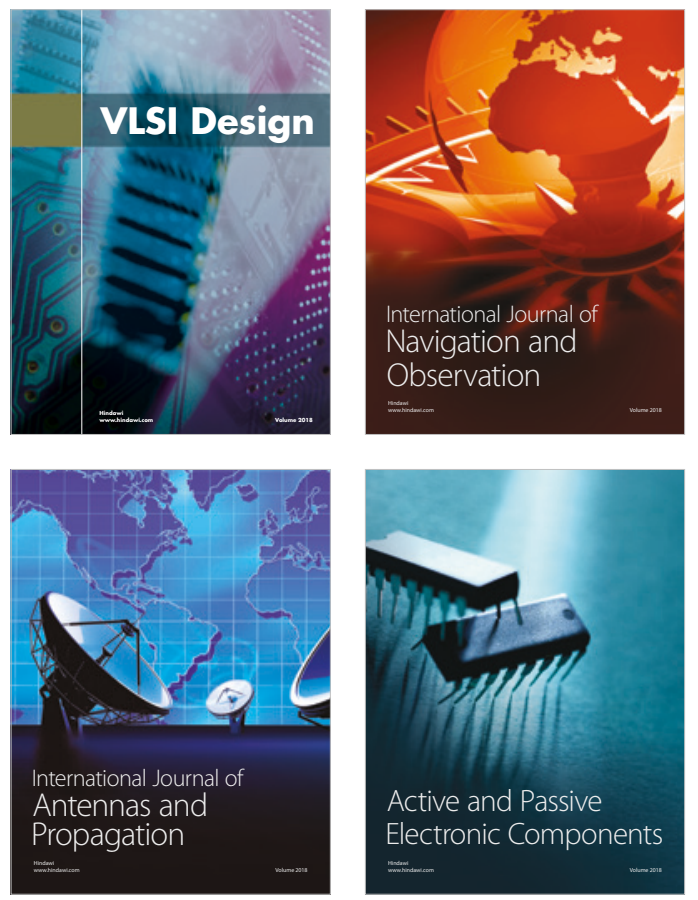
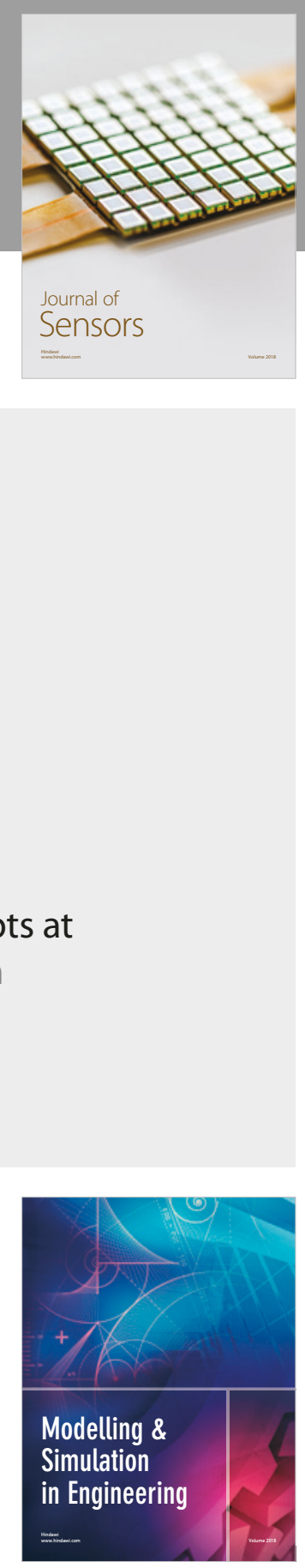

\section{Advances \\ Multimedia}
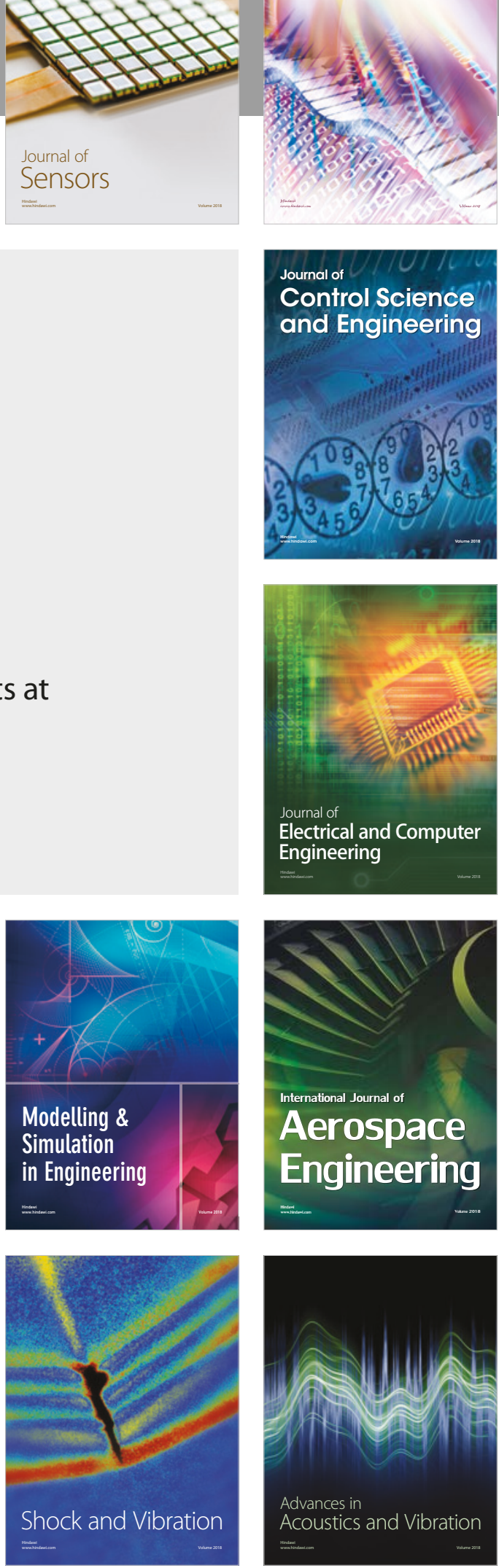